NASA/TM-2000-209648

\title{
Correlation of EBIC and SWBXT Imaged Defects and Epilayer Growth Pits in 6H-SiC Schottky Diodes
}

C.M. Schnabel and M. Tabib-Azar

Case Western Reserve University, Cleveland, Ohio

P.G. Neudeck and S.G. Bailey

Glenn Research Center, Cleveland, Ohio

H.B. Su and M. Dudley

State University of New York at Stony Brook, Stony Brook, New York

R.P. Raffaelle

Rochester Institute of Technology, Rochester, New York 
Since its founding, NASA has been dedicated to the advancement of aeronautics and space science. The NASA Scientific and Technical Information (STI) Program Office plays a key part in helping NASA maintain this important role.

The NASA STI Program Office is operated by Langley Research Center, the Lead Center for NASA's scientific and technical information. The NASA STI Program Office provides access to the NASA STI Database, the largest collection of aeronautical and space science STI in the world. The Program Office is also NASA's institutional mechanism for disseminating the results of its research and development activities. These results are published by NASA in the NASA STI Report Series, which includes the following report types:

- TECHNICAL PUBLICATION. Reports of completed research or a major significant phase of research that present the results of NASA programs and include extensive data or theoretical analysis. Includes compilations of significant scientific and technical data and information deemed to be of continuing reference value. NASA's counterpart of peerreviewed formal professional papers but has less stringent limitations on manuscript length and extent of graphic presentations.

- TECHNICAL MEMORANDUM. Scientific and technical findings that are preliminary or of specialized interest, e.g., quick release reports, working papers, and bibliographies that contain minimal annotation. Does not contain extensive analysis.

- CONTRACTOR REPORT. Scientific and technical findings by NASA-sponsored contractors and grantees.
- CONFERENCE PUBLICATION. Collected papers from scientific and technical conferences, symposia, seminars, or other meetings sponsored or cosponsored by NASA.

- SPECIAL PUBLICATION. Scientific, technical, or historical information from NASA programs, projects, and missions, often concerned with subjects having substantial public interest.

- TECHNICAL TRANSLATION. Englishlanguage translations of foreign scientific and technical material pertinent to NASA's mission.

Specialized services that complement the STI Program Office's diverse offerings include creating custom thesauri, building customized data bases, organizing and publishing research results ... even providing videos.

For more information about the NASA STI Program Office, see the following:

- Access the NASA STI Program Home Page at http://www.sti.nasa.gov

- E-mail your question via the Internet to help@sti.nasa.gov

- Fax your question to the NASA Access Help Desk at (301) 621-0134

- Telephone the NASA Access Help Desk at (301) 621-0390

- Write to:

NASA Access Help Desk

NASA Center for AeroSpace Information 7121 Standard Drive Hanover, MD 21076 
NASA/TM-2000-209648

\section{Correlation of EBIC and SWBXT Imaged Defects and Epilayer Growth Pits in 6H-SiC Schottky Diodes}

C.M. Schnabel and M. Tabib-Azar

Case Western Reserve University, Cleveland, Ohio

P.G. Neudeck and S.G. Bailey

Glenn Research Center, Cleveland, Ohio

H.B. Su and M. Dudley

State University of New York at Stony Brook, Stony Brook, New York

R.P. Raffaelle

Rochester Institute of Technology, Rochester, New York

Prepared for the

1999 International Conference on Silicon Carbide and Related Materials sponsored by North Carolina State University

Raleigh, North Carolina, October 10-15, 1999

National Aeronautics and

Space Administration

Glenn Research Center 


\section{Acknowledgments}

The authors would like to acknowledge the following employees at NASA Glenn: J.A. Powell, D. Larkin, C. Salupo, G. Beheim, J. Heisler, A. Trunek, L. Keys. CWRU work supported by NASA Glenn Grant NCC3-593. SUNY support from the U.S. Army Research Office under contract number DAAG559810392 (contract monitor Dr. John Prater), partially funded by the DARPA Microsystems Technology Office (Order\#E111/3 monitored by Dr. Dan Radack) and NASA Glenn. Topography carried out at the NSLS, at BNL, which is supported by the U.S. Department of Energy, contract number DE-AC02-98CH10886.

This report contains preliminary

findings, subject to revision as analysis proceeds.

\section{a}




\title{
Correlation of EBIC and SWBXT Imaged Defects and Epilayer Growth Pits in $6 \mathrm{H}-\mathrm{SiC}$ Schottky Diodes
}

\author{
C.M. Schnabel and M. Tabib-Azar \\ Case Western Reserve University \\ Glennan 517, 10900 Euclid Avenue \\ Cleveland, Ohio 44106, USA \\ P.G. Neudeck and S.G. Bailey \\ National Aeronautics and Space Administration \\ Glenn Research Center \\ MS 77-1, 21000 Brookpark Road \\ Cleveland, Ohio 44135, USA \\ H.B. Su and M. Dudley \\ State University of New York at Stony Brook \\ Stony Brook, New York 11794, USA \\ and \\ R.P. Raffaelle \\ Rochester Institute of Technology \\ Rochester, NY 14623
}

\begin{abstract}
We show the first direct experimental correlation between the presence of closed core screw dislocations in $6 \mathrm{H}-\mathrm{SiC}$ epilayers with recombination centers, as well as with some of the small growth pits on the epilayer surface in lightly-doped 6H-SiC Schottky diodes. At every SWBXT-identified closed core screw dislocation, an EBIC image showed a dark spot indicating a recombination center, and Nomarski optical microscope and Atomic Force Microscope (AFM) images showed a corresponding small growth pit with a sharp apex on the surface of the epilayer.

Introduction: The ability to readily identify the electrical properties of an extended crystal defect in a semiconductor is paramount in determining whether the defect influences the performance of various devices. Electron-beam-induced current (EBIC) measurement using the planar mapping technique enables quantitative analysis and spatial visualization of recombination centers that reduce the diffusion length of minority carriers in $6 \mathrm{H}-\mathrm{SiC}$ Schottky diodes $[1,2,3]$. Such a procedure coupled with synchrotron white-beam $\mathrm{x}$-ray topography (SWBXT), through which closed core screw dislocations may be identified by their stress signature in the crystal lattice [4], gives insight into the effects of these defects on the minority carrier diffusion length. The SWBXT image may also be correlated to the as-grown homoepilayer surface by comparison with Nomarski optical microscopy and atomic force microscopy (AFM) images.
\end{abstract}

Experimental Procedure: Following the growth of a $3.5 \mu \mathrm{m}$ thick $1.2 \times 10^{16} \mathrm{~cm}^{-3} \mathrm{n}$-type homoepilayer on a $3.5^{\circ}$ off-axis commercial $6 \mathrm{H}-\mathrm{SiC}$ substrate [5] by CVD [6], we generated a map of closed core screw dislocations using SWBXT [4]. The wafer backside was polished prior to SWBXT to ensure sufficient X-ray image quality that individual closed core screw dislocations were clearly resolvable throughout the entire sample. Following deposition and annealing of a backside Ni ohmic contact $\left(\sim 925^{\circ} \mathrm{C}, 5\right.$ minutes in argon ambient), thin gold Schottky contacts (approx. $400 \AA$ thick) of up to $0.86 \mathrm{~mm} \mathrm{x} 0.86 \mathrm{~mm}$ in area were then patterned on the epilayer surface using E-beam evaporation and lift-off photolithography. High magnification $(400 \mathrm{X})$ Nomarski optical images of the surface features of individual dies were made. With the assistance of AFM analysis, the observed features evident on the Au Schottky contacts were categorized as either 
particulates on the top surface of the Schottky metal due to sample handling, or growth pits in the as-grown epilayer observable through the thin metallization.

EBIC images were generated by raster-scanning the $25 \mathrm{keV}$ electron-beam across the entirety of the die while measuring the collected current as a function of position. Lighter shades correspond to higher collected currents indicating longer minority carrier lifetime, while areas of enhanced minority carrier recombination (i.e., lower carrier lifetime and lower collected currents) are imaged as dark spots [1]. Because raw images collected by SWBXT and EBIC were somewhat distorted, computer image processing was needed to restore raw images to the proper aspect ratio corresponding to the proper aspect ratio of the original sample. All images were digitally scanned into a computer so that the images could be undistorted, scaled, and digitally overlaid as separate image layers using the four comers of the $7.5 \mathrm{~mm} \times 6 \mathrm{~mm}$ rectangular sample as common reference coordinates. The computer contrast enhancement of images and creation of partially transparent derived layers expedited correlation of data from all three measurements.

Results: The figures below illustrate the same device region showing part of a $0.86 \mathrm{~mm} \times 0.86 \mathrm{~mm}$ Schottky diode recorded by SWBXT (Figure 1), EBIC (Figure 2), and optical microscope (Figure 3, with AFM inset of a small growth pit). All the closed core screw dislocations revealed in Figure 1 are clearly reflected by correspondingly located dark spots in the EBIC image of Figure 2. It is readily apparent, however, that there are additional dark spots in the EBIC image for which no screw dislocation is present. While less obvious in Figure 3 due to their very small size, small growth pits typical of the AFM inset were also identified at every screw dislocation. However, not all EBIC-revealed recombination centers and not all small growth pits are associated with screw dislocations. The small growth pits correlated with screw dislocations appear similar in size and shape, while those that are not associated with screw dislocation sometimes have different shapes. Some EBIC dark spots and some epilayer small growth pits appear completely independent in that they show up in none of the other images (such as RC-1 in Figure 2 and GP-1 in Figure 3). Most, but not all, growth pits unassociated with screw dislocations did not yield strong EBIC signatures. Table 1 shows the defect statistics recorded at six locations consisting of four different $860 \mu \mathrm{m}$ x $860 \mu \mathrm{m}$ diodes plus two similar-sized areas consisting of many smaller patterned Schottky contacts.

Screw dislocations significantly reduce the effective diffusion length of carriers in the sample. Figure 4 shows the diffusion length as a function of position across screw dislocation SD-1 shown in Figure 2. The diffusion length is calculated on the order of $3.4 \mu \mathrm{m}$ far from the defect, but drops around 30 percent to as low as $2.4 \mu \mathrm{m}$ near the center of the defect. This behavior is typical of the screw dislocations measured in this $6 \mathrm{H}-\mathrm{SiC}$ sample.

Figure 5 shows the AFM sectional data plot taken through the middle of the small growth pit associated with SD-1, as illustrated by the white line in the middle of the AFM inset of Figure 3. One end of the metalcovered small growth pit consists of a sharp apex of at least $18 \mathrm{~nm}$ in depth. This data is typical of all the small growth pits associated with screw dislocations measured by AFM on this sample. Such sharp interface features could conceivably enhance carrier emission/leakage from the semiconductor impacting SiC Schottky diode I-V properties as well as MOS insulator reliability. Once very small area devices have been fabricated (i.e., small enough that some are free of certain defects), a comprehensive study of Schottky I-V properties as a function of imaged defects is planned. If successful, such a study might be able to conclusively link specific kinds of crystal defects to important electrical anomalies observed in the SiC Schottky diode literature (particularly Refs. [2], [7], and [8]).

Conclusion: All screw dislocations result in EBIC-identified minority carrier recombination centers in the $\mathrm{SiC}$ epilayer, and in small growth pits at the sample surface. However, not all growth pits are due to screw dislocations. Not all minority carrier recombination centers are due to screw dislocations. 


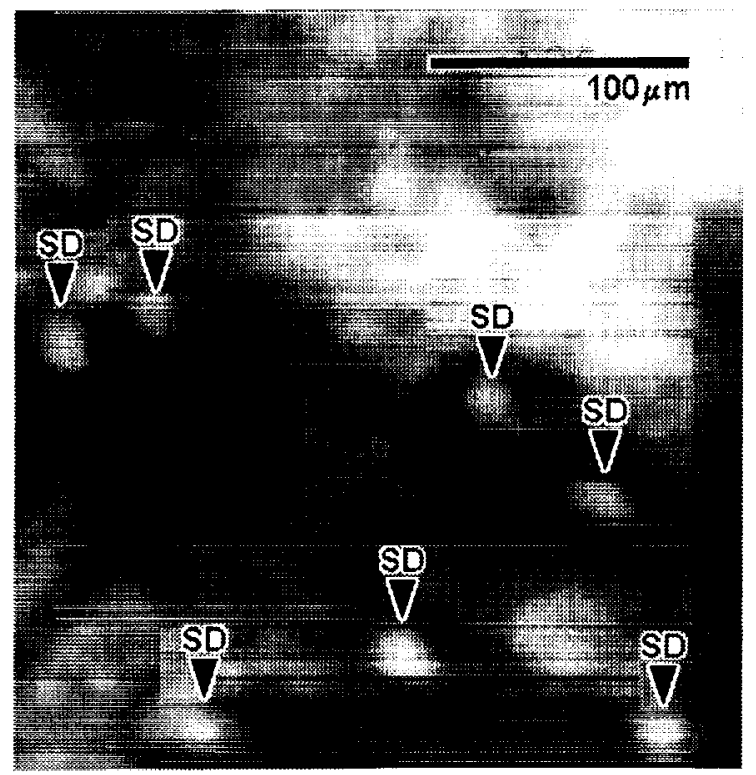

Fig. 1. SWBXT map of a selected diode section. The lighter spots in the image are elementary screw dislocations causing high stress regions in the crystal lattice.

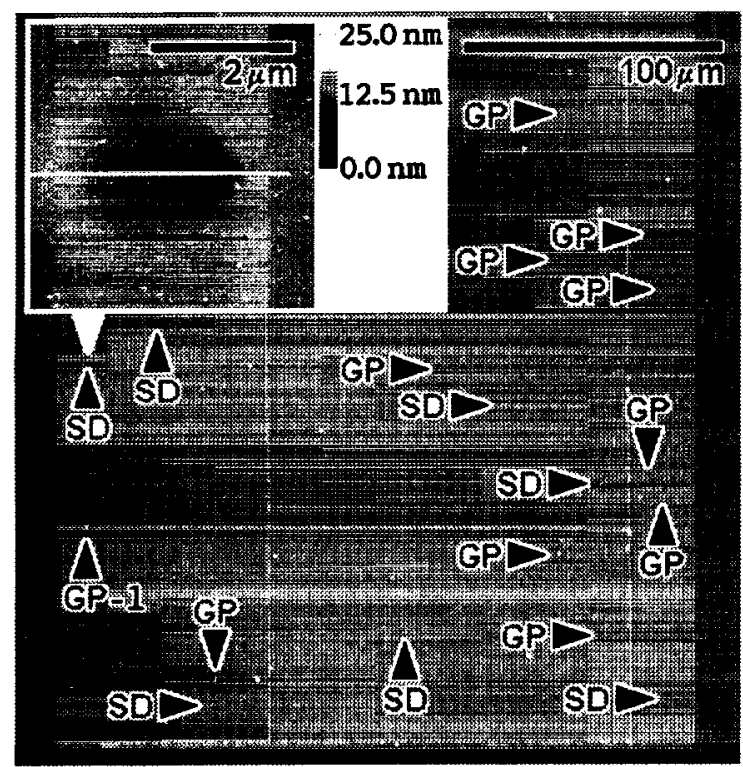

Fig. 3. Nomarski image of a selected diode section. Both growth pits and other particulates are evident on the sample surface. The inset shows an AFM image of a growth pit typical of a screw dislocation.

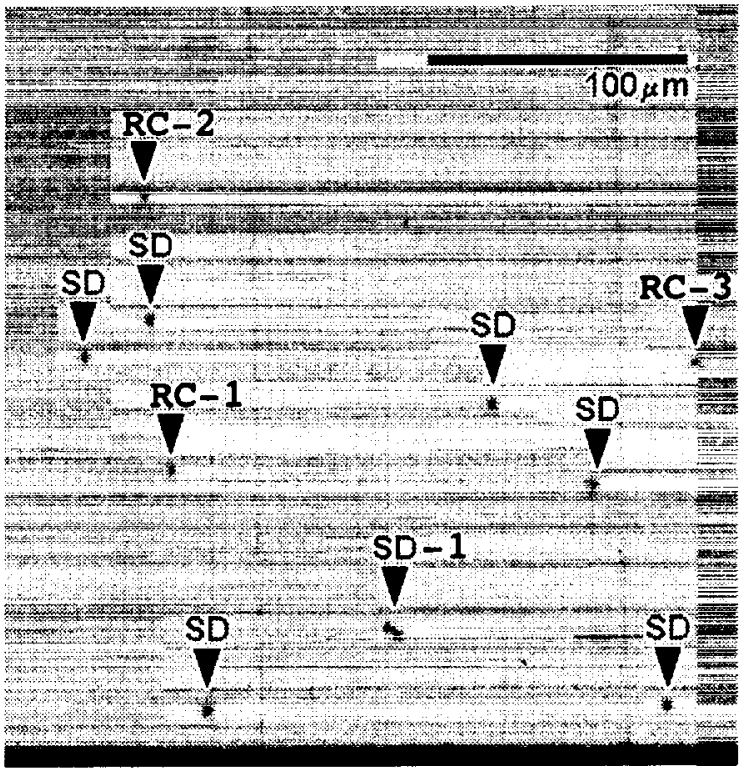

Fig. 2. EBIC image of a selected diode section. Darker regions indicate lower collected current, which corresponds to a reduction in the effective diffusion length.

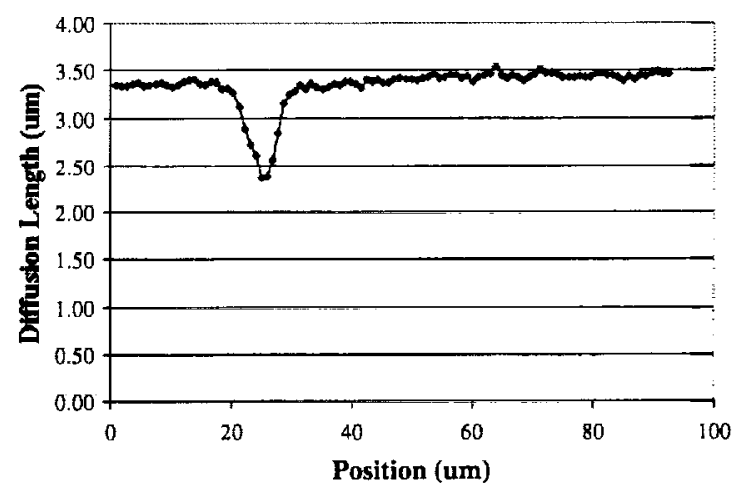

Fig. 4. Diffusion length as a function of position extracted from the EBIC linescan, as shown by the white line across SD-1 of Figure 2. 


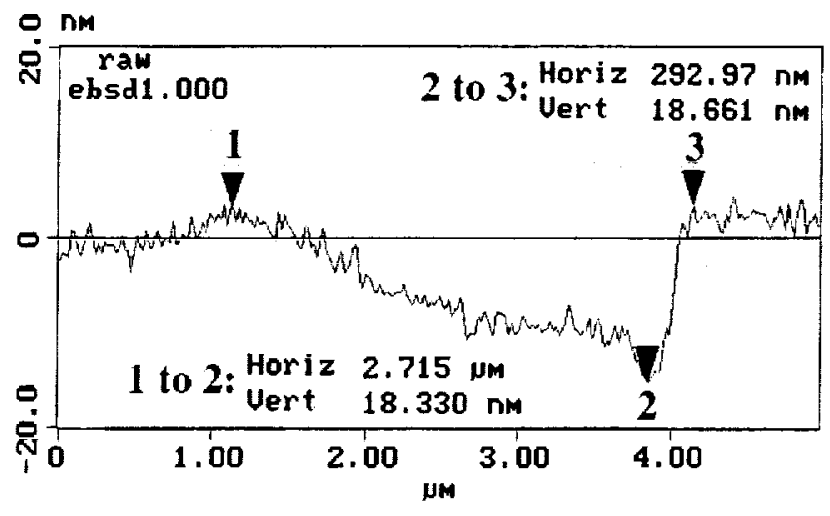

Fig. 5. AFM sectional data plot taken through the middle of the small growth pit associated with SD-1, as illustrated by the white line in the middle of the AFM inset of Figure 3. One end of the metal-covered small growth pit consists of a sharp apex of at least $18 \mathrm{~nm}$ in depth. This data is typical of all the small growth pits associated with screw dislocations measured by AFM on this sample.

Table 1 Number of defects on different $1 \mathrm{~mm} \times 1 \mathrm{~mm}$ dies by observation category.

\begin{tabular}{|c|c|c|c|c|c|c|}
\hline Die I.D. Label on Chip $->$ & $\mathrm{Bd}$ & Dc & $\mathrm{Db}^{5}$ & $D f^{5}$ & $\mathrm{Ab}^{3,5}$ & $\mathrm{Bc}^{3.5}$ \\
\hline EBIC recombination centers & 126 & 105 & 98 & 161 & 31 & 32 \\
\hline $\begin{array}{l}\text { SWBXT identified screw } \\
\text { dislocations over die(s) }^{1}\end{array}$ & 40 & 27 & 41 & 43 & 7 & 10 \\
\hline $\begin{array}{l}\text { Nomarski identified small } \\
\text { growth pits }\end{array}$ & 176 & 159 & - & - & - & - \\
\hline $\begin{array}{l}\text { Recombination centers } \\
\text { matching screw dislocations }{ }^{2}\end{array}$ & $36^{4}$ & 27 & 41 & 43 & 7 & 10 \\
\hline \begin{tabular}{|l|}
$\begin{array}{l}\text { Growth pits matching screw } \\
\text { dislocations }\end{array}$ \\
\end{tabular} & 40 & 27 & - & - & - & - \\
\hline \multicolumn{7}{|c|}{$\begin{array}{l}\text { 1. Large areas of high stress are counted as a screw dislocation, although it may be due to many screw } \\
\text { dislocations or another defect such as a micropipe. } \\
\text { 2. If one growth pit or recombination center is within approx. } 20 \mu \mathrm{m} \text { of the screw dislocation it is considered } \\
\text { correlated with that screw dislocation. } \\
\text { 3. Ab and } \mathrm{Bc} \text { represent many smaller dies that lie close together, and therefore have much smaller measured } \\
\text { areas than dies Bd, Dc, Db, and Df. } \\
\text { 4. Probe tip and contact damage obscured EBIC observation of some screw dislocations. } \\
\text { 5. Growth pit data not collected on die Db, Df, Ab, and Bc. }\end{array}$} \\
\hline
\end{tabular}

\section{References}

[1] H. J. Leamy, J. Appl. Phys. 53 (1982), p. R51.

[2] M. Bhatnagar, et al., IEEE Trans. Electron Devices 43 (1996), p. 150.

[3] M. Tabib-Azar, et al., J. Appl. Phys. 84 (1998), p. 3986.

[4] M. Dudley and X. Huang, this conference.

[5] Cree Research, Inc., 4600 Silicon Drive, Durham, NC 27703.

[6] D. J. Larkin, MRS Bulletin 22 (1997), p. 36.

[7] R. Raghunathan and B. J. Baliga, Appl. Phys. Lett. 72 (1998), p. 3196.

[8] D. Defives et al., IEEE Trans. Electron Devices 46 (1999), p. 449. 


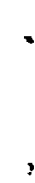

? 
Public reporting burden for this collection of information is estimated to average 1 hour per rasponse, including the time for reviewing insiructions, searching existing data sources, gathering and maintaining the data needed, and completing and reviewing the collection of information. Send comments regarding this burden estimate or any other aspect of this collection of information, including suggestions for reducing this burden, to Washington Headquarters Services, Directorate for information Operations and Peports, 1215 Jefferson Davis Highway, Suite 1204, Arlington, VA 22202-4302, and to the Office of Management and Budget, Paperwork Reduction Project (0704.0188), Washington, DC 20503.

\begin{tabular}{|l|l|l|}
\hline 1. AGENCY USE ONLY (Leave blank) & 2. AEPORT DATE & 3. REPORT TYPE AND DATES COVERED
\end{tabular}

\begin{tabular}{|l|l|l}
\hline & February 2000 & Technical Memorandum \\
\hline
\end{tabular}

\begin{tabular}{|l|l|}
\hline 4. TITLE AND SUBTITLE & 5. FUNDING NUMBERS
\end{tabular}

Correlation of EBIC and SWBXT Imaged Defects and Epilayer Growth

Pits in 6H-SiC Schottky Diodes

6. AUTHOR(S)

C.M. Schnabel, M. Tabib-Azar, P.G. Neudeck, S.G. Bailey, H.B. Su,

M. Dudley, and R.P. Rafaelle

7. PERFORMING ORGANIZATION NAME(S) AND ADDRESS(ES)

National Aeronautics and Space Administration

John H. Glenn Research Center at Lewis Field

Cleveland, Ohio 44135-3191

WU-505-23-2Q-00

9. SPONSORING/MONITORING AGENCY NAME(S) AND ADDRESS(ES)

National Aeronautics and Space Administration

Washington, DC 20546-0001

8. PERFORMING ORGANIZATION

REPORT NUMBER

E-11996

\section{SUPPLEMENTARY NOTES}

Prepared for the 1999 International Conference on Silicon Carbide and Related Materials sponsored by North Carolina State University, Raleigh, North Carolina, October 10-15, 1999. C.M. Schnabel and M. Tabib-Azar, Case Western Reserve University, Glennan 517, 10900 Euclid Avenue, Cleveland, Ohio 44106; P.G. Neudeck and S.G. Bailey, NASA Glenn Research Center; H.B. Su and M. Dudley, State University of New York at Stony Brook, Stony Brook, New York 11794; and R.P. Rafaelle, Rochester Institute of Technology, Rochester, New York 14623. Responsible person, P.G. Neudeck, organization code 5510, (216) 433-8902.

12a. DISTRIBUTION/AVAILABILITY STATEMENT 12b. DISTRIBUTION CODE

Unclassified - Unlimited

Subject Categories: 33 and 76

Distribution: Standard

This publication is available from the NASA Center for AeroSpace Information, (301) 621-0390.

13. ABSTRACT (Maximum 200 words)

We show the first direct experimental correlation between the presence of closed core screw dislocations in $6 \mathrm{H}-\mathrm{SiC}$ epilayers with recombination centers, as well as with some of the small growth pits on the epilayer surface in lightlydoped 6H-SiC Schottky diodes. At every SWBXT-identified closed core screw dislocation, an EBIC image showed a dark spot indicating a recombination center, and Nomarski optical microscope and Atomic Force Microscope (AFM) images showed a corresponding small growth pit with a sharp apex on the surface of the epilayer.

14. SUBJECT TEAMS
Defects; Screw dislocations; Growth pits; Recombination centers; Diffusion length;

Synchrotron white-bean $\mathrm{x}$-ray topography (SWBXT); Electron beam induced current (EBIC); Silicon carbide; Diffusion length; Schottky diodes; Minority carriers

17. SECURITY CLASSIFICATION OF REPORT

Unclassified 8. SECURITY CLASSIFICATION OF THIS PAGE

Unclassified

\section{SECUAITY CLASSIFICATION} OF ABSTRACT
SPONSORING/MONITORING

NASA TM-2000-209648
Unclassified
15. NUMBER OF PAGES

10. PRICE CODE

$\mathrm{AO} 2$

20. LIMITATION OF ABSTRACT 